\title{
ANÁLISE ESTRUTURAL DE SILOS METÁLICOS PRISMÁTICOS
}

\author{
Structural analysis of prismatic metallic silos
}

\author{
José Pinheiro Lopes Neto ${ }^{1}$, José Wallace Barbosa do Nascimento ${ }^{2}$, Carlito Calil Junior ${ }^{3}$
}

\begin{abstract}
RESUMO
Nos últimos anos, o crescimento da agricultura brasileira tem forçado vários setores a se adequarem aos padrões produtivos com o intuito de se manterem competitivos, frente ao processo de globalização econômica. Nesse contexto, as fábricas de ração avícola tendem a buscar novas alternativas que favoreçam a produção e reduzam custos sem afetar a qualidade do produto final. Entre essas alternativas, destaca-se o uso de silos verticais por facilitar o processo de confecção das rações e eliminar os grandes depósitos horizontais. Diante dessa possibilidade, objetivou-se, com a presente pesquisa, estudar as tensões nas paredes em conformação ziguezague de um silo metálico prismático $2 \mathrm{~m}$ x $1 \mathrm{~m}$ e comparar os resultados obtidos com teorias e normas. Para o cálculo das tensões, utilizaram-se os métodos simplificados de Ravenet e Troitsky. Para a obtenção dos esforços reais nas paredes, utilizaram-se extensômetros elétricos. Dessa forma, conclui-se que, tanto a teoria de Ravenet quanto de Troistky, podem ser recomendadas para o dimensionamento de silos prismáticos por apresentarem boa aproximação com valores experimentais.
\end{abstract}

Termos para indexação: Soja em pelets, tensão, conformação ziguezague.

\section{ABSTRACT}

Recently Brazil has undergone agricultural growth that has forced several sectors to adjust their business structure to maintain competitiveness within the process of economic globalization. In this context, the poultry production has focused on new alternatives to increase productivity and reduce costs without affecting the quality of the final product. Among these alternatives, the use of vertical silos due to their capacity and ease of accurate feed ingredient rationing and eliminate large horizontal warehouses. The present research has focused on the stresses in rectangular, hopper bottom bins with a unique zigzag corrugation. The model bin was $2 \mathrm{~m} \times 1 \mathrm{~m}$ with a hopper and the stresses obtained were compared to theories and standards. The stresses were estimated using Ravenet and Troitsky's simplified methods and compared to the experimental results. Strain gauges were used to obtain data on the stress within the bin walls. One concluded that either Ravenet or Troitsky's theory may be recommended for the design of rectangular silos since they provide a high level of accuracy compared to experimental values.

Index terms: Pelletized soybean, stress, zigzag corrugation.

(Recebido em 21 de dezembro de 2005 e aprovado em 28 de fevereiro de 2008)

\section{INTRODUÇÃO}

A cada dia, o Brasil tende a se consolidar no mercado mundial como uma força econômica devido à adoção de uma política agressiva de produção e exportação agrícola, tendo como principais produtos de comércio: grãos (a soja em destaque), carnes bovina, suína, avícola e seus subprodutos. Em relação às carnes, para que o país possa manter-se economicamente competitivo, é necessário que ações visando uma melhoria na qualidade alimentar dos animais sejam implementadas, não somente no que diz respeito às suas características nutricionais, mas também aos métodos de elaboração, conservação e distribuição.

Diante dessa necessidade, surge a importância de dominar a tecnologia de construção de silos muitos deles utilizados em fábricas de rações responsáveis por abastecer outras unidades agrícolas dando, assim, seguimento ao restante da cadeia de produção animal. Conforme Nascimento (1996), tais fábricas necessitam basicamente de dois tipos de silos: um para produtos granulares e outro para produtos pulverulentos não apresentando, os grãos, problemas com relação ao fluxo, enquanto que o segundo exige fluxo controlado.

Sabe-se hoje que as novas fábricas de ração possuem forte tendência à arquitetura vertical devido à uma crescente valorização territorial e à carência de maior facilidade e rapidez nas etapas de produção, a fim de atender à crescente demanda do mercado consumidor. Com isso, o estudo e adoção de silos verticais despontam como grande alternativa de reformulação do conceito de fábricas de ração, por atender tanto às exigências de taxas de ocupação quanto ao que diz respeito aos processos produtivos.

\footnotetext{
Engenheiro Agrícola, Mestre em Construções Rurais e Ambiência, Professor - Unidade Acadêmica de Agronomia e Tecnologia de Alimentos/UATA Universidade Federal de Campina Grande/UFCG - Rua Coronel João Leite, 517 - Centro - 58840-000 - Pombal, PB - lopesneto@gmail.com 'Engenheiro Agrícola, PhD em Estruturas de Silos, Professor - Unidade Acadêmica de Engenharia Agrícola/UAEAg - Universidade Federal de Campina Grande/UFCG - Rua Aprígio Veloso, 882 - Bodocongó - 58109-900 - Campina Grande, PB - wallace@deag.ufcg.edu.br ${ }^{3}$ Engenheiro Civil, Doutor em Engenharia Industrial, Professor Titular - Departamento de Engenharia de Estruturas/DEE - Avenida Trabalhador Sãocarlense, 400 - Centro - 13566-590 - São Carlos, SP - calil@sc.usp.br
} 
Entre os tipos de silos existentes, os silos verticais metálicos prismáticos destacam-se pelo fato de poderem ser multicelulares facilitando a transilagem e proporcionando maior facilidade de operação dos equipamentos e precisão na confecção das rações (NASCIMENTO, 1996). Mas, apesar dessas vantagens, silos verticais prismáticos ainda são pouco utilizados, parte devido ao simples desconhecimento de seus benefícios, parte em razão da escassez de conhecimentos técnicos necessários ao seu projeto e construção.

Segundo Brown \& Nielsen (1998), o projeto e comportamento de silos retangulares ou quadrados são muito diferentes dos silos cilíndricos. Grandezas como pressão e deslocamento, sua interação e importância no comportamento de silos prismáticos ainda são pouco compreendidas. De acordo com Calil Junior et al. (1997), silos prismáticos de paredes conformadas são mais eficientes e econômicos pelo fato da conformação impor maior rigidez às paredes. De acordo com Ravenet (1992), existem duas conformações de paredes bastante utilizadas nas indústrias que são a conformação trapezoidal e a ziguezague.

Objetivou-se, na presente pesquisa, estudar o comportamento estrutural das paredes de um silo metálico prismático de configuração ziguezague e comparar os resultados obtidos com teorias e pesquisas existentes contribuindo, assim, para um melhor entendimento de tais construções.

\section{MATERIAL E MÉTODOS}

Os ensaios foram realizados no Laboratório de Construções Rurais e Ambiência (LaCRA) da Universidade Federal de Campina Grande (UFCG), entre os meses de Fevereiro e Maio de 2005.

O corpo do silo apresenta secção retangular $2 \mathrm{mx} 1 \mathrm{~m}$, de altura $1,8 \mathrm{~m}$ e $3,6 \mathrm{~m}^{3}$ de capacidade de armazenagem. As paredes, construídas de chapas de aço SAE 1010 de espessura nominal igual a $0,91 \mathrm{~mm}$, são formadas por três ondas (superior, central e inferior), em conformação ziguezague com $70^{\circ}$ de inclinação com a horizontal sendo cada onda composta por duas partes (Superior e Inferior). A tremonha, concêntrica com 1,25 $\mathrm{m}^{3}$ de capacidade volumétrica, foi construída com chapas metálicas de $1,5 \mathrm{~mm}$ de espessura. Apresenta geometria trapezoidal com inclinação de $54^{\circ} \mathrm{com}$ a horizontal em relação ao lado de $2 \mathrm{~m}$ e orifício de descarga de $0,24 \mathrm{~m}$ x $0,14 \mathrm{~m}$.

A seguir (Figura 1), são apresentados maiores detalhes do silo estudo.
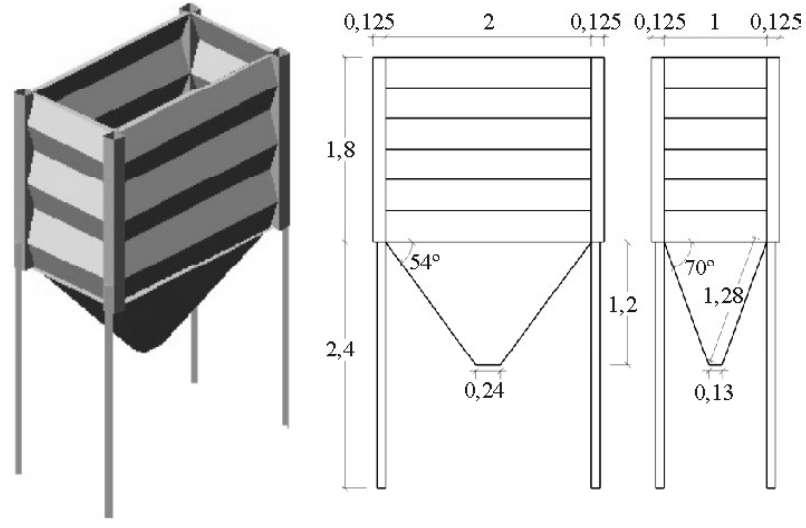

Figura 1 - Vista e dimensões do silo estudado (valores em metros).

Para a medição das deformações, foram utilizados extensômetros elétricos conectados a um sistema de aquisição de dados denominado SPIDER 8 sendo os dados analisados através do software Catman 3.0. Para a determinação das propriedades de fluxo da soja peletizada (produto empregado nos ensaios), utilizou-se o aparelho de cisalhamento direto de translação (TSG 70-140), com base no aparelho de cisalhamento de Jenike (Jenike Shear Cell), seguindo-se a metodologia proposta pela BMHB (1985). Para o ensaio de atrito do produto com a parede de aço rugoso, utilizou-se um conjunto de cargas decrescentes de $50 \mathrm{~N}$ a $4,4 \mathrm{~N}$ possibilitando, dessa forma, construir gráficos de tensão normal versus cisalhamento.

Para o cálculo das pressões horizontais teóricas nas paredes do silo, optou-se por quatro normas internacionais sendo elas: DIN 1055 (DIN, 1987), ISO 11697 (ISO, 1995), EUROCODE 1 (EUROCODE, 1995) e AS 3774 (AS, 1990), por serem largamente recomendadas para dimensionamento e pesquisas, em função de sua eficácia. Para o cálculo das tensões nas paredes do silo, foram adotadas as teorias simplificadas de dimensionamento propostas por Ravenet (1992) (viga bi-engastada) e Troitsky (1982) (viga biapoiada).

Foram instrumentadas apenas duas paredes do silo, sendo denominadas, para facilidade de entendimento, de Parede I aquela cujo comprimento do vão é igual a um metro e de Parede II aquela cujo comprimento do vão é igual a dois metros. Foram escolhidos dois pontos para a instalação dos sensores em cada parede sendo eles, unicamente, no centro do vão das partes superior e inferior da onda central. Os extensômetros elétricos foram instalados na superfície externa da onda central nos sentidos transversal e longitudinais (Figura 2), a fim de se determinar as deformações no estado duplo de tensão. 


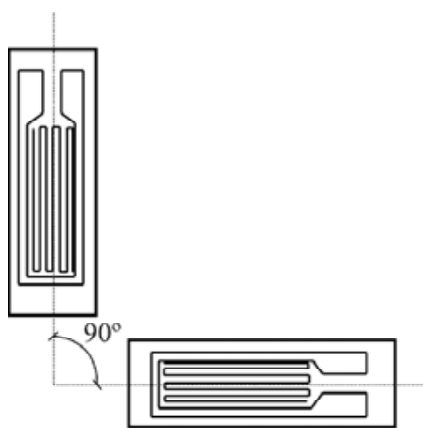

Figura 2 - Posicionamento dos extensômetros elétricos.

A coleta dos dados realizou-se a uma freqüência de $1 \mathrm{hz}$, durante os processos de carregamento e descarregamento concêntricos do silo sendo os mesmos divididos em três etapas consistindo, cada etapa, de três repetições. Na primeira etapa, Fase Instantânea, ocorreu o carregamento do silo com soja peletizada e após 30 minutos, efetuou-se seu completo descarregamento. $\mathrm{Na}$ segunda etapa, Fase 24 horas, o silo foi carregado e somente descarregado depois de completadas 24 horas do início do processo. Na última etapa, Fase 48 horas, o silo foi carregado e somente descarregado $48 \mathrm{~h}$ após o início do processo.

\section{RESULTADOS E DISCUSSÃO}

Através dos ensaios de granulometria, observouse que o maior valor de porcentual retido acumulado para a soja em pelets foi de $32,16 \%$, para a peneira de malha $4 \mathrm{~mm}$. Conforme classificação dos produtos sólidos proposta por Calil Junior (1984), pode-se considerar a soja em pelets como um produto de característica granular. No momento dos ensaios, a soja em pelets encontrava-se com teor de umidade de $11 \%$ (base úmida).
Apesar de não haver registros científicos conhecidos sobre as propriedades de fluxo da soja em pelets (Tabela 1), pode-se destacar que os ângulos de atrito interno e ângulo efetivo de atrito interno encontram-se próximos aos obtidos por Bandeira et al. (1999), para ração avícola. É importante salientar que os valores apresentados das propriedades de fluxo foram determinados apenas através do ensaio de cisalhamento instantâneo.

A seguir, são apresentados valores de tensões a partir das deformações para as Fases Instantâneas, 24 horas e 48 horas, para as situações estática e dinâmica nas Paredes I e II. Os valores negativos foram dispostos nos gráficos em valor absoluto a fim de permitir uma melhor análise comparativa entre os dados.

Através da Figura 3, observam-se os valores máximos de tensão para as duas partes que compõem as ondas centrais das Paredes I e II nas condições estática e dinâmica. Em análise da condição estática na Parede I, a parte inferior assumiu valor máximo igual a $30 \mathrm{MPa}$ enquanto que a metade superior alcançou cerca de -12MPa. $\mathrm{O}$ valor negativo determinado para a parte superior significa um esforço de compressão de suas fibras externas influenciada por uma flexão ocorrida na parte inferior, no momento do carregamento do silo. Segundo Troitsky (1982), as ações de carregamentos originam-se nas paredes de silos prismáticos complexos esforços de tração, compressão, flexão e torção e, que a escassez documentos científicos dificulta um melhor entendimento do comportamento estrutural das paredes no processo de descarregamento.

Na situação dinâmica, o valor máximo de tensão registrado para o descarregamento foi $31 \mathrm{MPa}$ para a metade inferior, ficando esse valor cerca de $35 \%$ abaixo do valor máximo obtido por Nascimento \& Calil Junior (1998) ao

Tabela 1 - Propriedades de fluxo instantâneas obtidas para a soja em pelets.

\begin{tabular}{lcc}
\hline & \multicolumn{2}{c}{ Propriedades de fluxo da soja em pelets } \\
\hline Peso específico consolidado $(\gamma)$ & $\gamma_{\mathrm{i}}\left(\mathrm{kN} / \mathrm{m}^{3}\right)$ & $\gamma_{\mathrm{s}}\left(\mathrm{kN} / \mathrm{m}^{3}\right)$ \\
Ângulo de atrito interno $(\varnothing)$ & 5,1 & $\emptyset_{\mathrm{s}}\left({ }^{\circ}\right)$ \\
\cline { 2 - 3 } & $\emptyset_{\mathrm{i}}\left(^{\circ}\right)$ & 38,3 \\
\hline Ângulo efetivo de atrito interno $(\delta)$ & 28,0 & $\delta_{\mathrm{s}}\left(^{\circ}\right)$ \\
Ângulo de atrito com aço rugoso $\left(\varnothing_{\mathrm{w}}\right)$ & $\delta_{\mathrm{i}}\left({ }^{\circ}\right)$ & 40,3 \\
\hline
\end{tabular}

Os índices "i" e "s" indicam os limites inferior e superior, respectivamente. 
determinar as tensões em um painel metálico de $1 \mathrm{~m}$ de vão. A diferença entre os valores das duas pesquisas pode ser explicada pelo fato do carregamento utilizado no estudo de painéis ter sido normal ao plano adotado ocasionando, dessa forma, distribuição de cargas diferente da ocorrida nesse experimento.

Para a Parede II ainda na Figura 3, pôde-se observar que a tensão na situação estática na metade inferior da onda atingiu valor de 51MPa enquanto que, para a metade superior, o valor máximo foi de -12MPa. Tal variação pode ser explicada, novamente, pela influência da metade inferior sobre a superior já que, com o decorrer do carregamento do silo, a carga crescente na metade inferior fez com que a superior sofresse uma inversão de comportamento ocasionando compressão de suas fibras externas. Para a condição dinâmica, ocorreu elevação da tensão na parte inferior até $58 \mathrm{MPa}$, sendo esse valor 1,14 vezes superior ao máximo registrado no carregamento. Nessa parede, o valor máximo de tensão obtido no descarregamento ficou cerca de $13 \%$ acima do registrado por Nascimento \& Calil Junior (1998), em painéis de $2 \mathrm{~m}$ de vão.



Figura 3 - Tensões nas Paredes I e II na Fase Instantânea.

Para a condição estática na Fase 24 Horas na Parede I (Figura 4), destaca-se o máximo valor obtido pela parte inferior da onda igual a 30MPa. Para a condição dinâmica na mesma parede, os valores máximos registrados para a parte inferior e superior foram $32 \mathrm{MPa}$ e $-17 \mathrm{MPa}$, respectivamente. A máxima tensão registrada na parte inferior para o descarregamento nessa parede foi $10 \%$ inferior à obtida por Nascimento \& Calil Junior (1998), para o painel de $1 \mathrm{~m}$ de vão. Ainda na Figura 4, observa-se valor máximo para a parte inferior igual a 52MPa, para a condição estática na Parede II. Para a situação dinâmica, os valores extremos para a parte inferior e superior foram iguais a $62 \mathrm{MPa}$ e $-18 \mathrm{MPa}$, respectivamente. Nascimento \& Calil Junior (1998) encontraram, para o painel de $2 \mathrm{~m}$ de vão, uma tensão longitudinal de $52 \mathrm{MPa}$ o que representa uma diferença de quase 20\%, quando comparada à tensão máxima obtida nesse experimento.

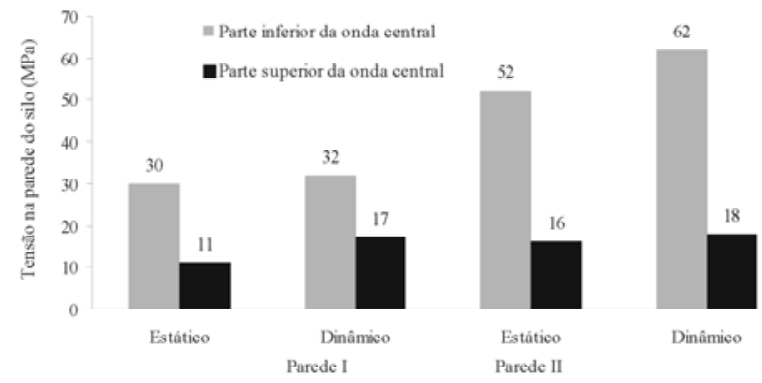

Figura 4 - Tensões nas Paredes I e II na Fase 24 horas.

Na condição estática da Parede I, na Fase 48 horas (Figura 5), os maiores valores de tensão foram de 29MPa e -12MPa para as partes inferior e superior, respectivamente. Para a condição dinâmica, a parte inferior da onda atingiu tensão máxima igual a 33MPa. Analisando-se os valores extremos da parte inferior da onda, pode-se afirmar que tal valor encontra-se cerca de $30 \%$ inferior à tensão descrita por Nascimento \& Calil Junior (1998). Ainda na Figura 5, destaca-se o valor máximo na parte inferior da onda na condição estática, para a Parede II igual a 51MPa. Para o descarregamento, o valor máximo registrado foi na parte inferior da onda central, sendo igual a 65MPa.
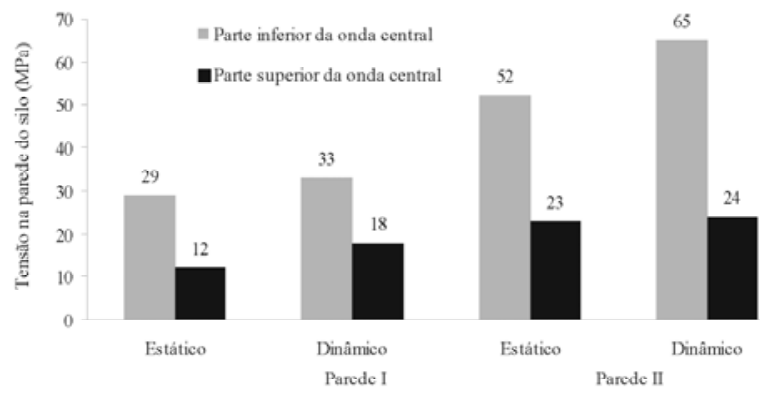

Figura 5 - Tensões nas Paredes I e II na Fase 48 horas.

\section{Comparação entre tensões teóricas e experimentais}

Tomando-se como base os valores máximos de tensão obtidos para a parte inferior da onda central na Parede I, nota-se na Figura 6 (Fase Instantânea), que a teoria associada à norma de pressão que melhor representou a tensão experimental no carregamento foi a teoria de Troitsky, combinada à norma AS 3774 (AS, 1990) superestimando-a em 10\%. Já para a condição dinâmica (Figura 7), a teoria de Ravenet em associação à mesma 
norma AS 3774 (AS, 1990) foi a que apresentou valor mais próximo ao experimental.

Em análise aos dados encontrados para a parede de II, na Figura 8, observa-se que a teoria que melhor representou os esforços na parede foi a de Troitsky, em conjunto com as normas ISO 11697 (ISO, 1995) e EUROCODE 1 (EUROCODE, 1995), sendo 2\% maior que a tensão no carregamento. Para o descarregamento, na Figura 9, novamente a teoria de Troitsky em conjunto à norma AS 3774 (AS, 1990) demonstrou-se mais adequada ao se igualar à máxima tensão experimental.



Figura 6 - Tensões estáticas (Parede I)

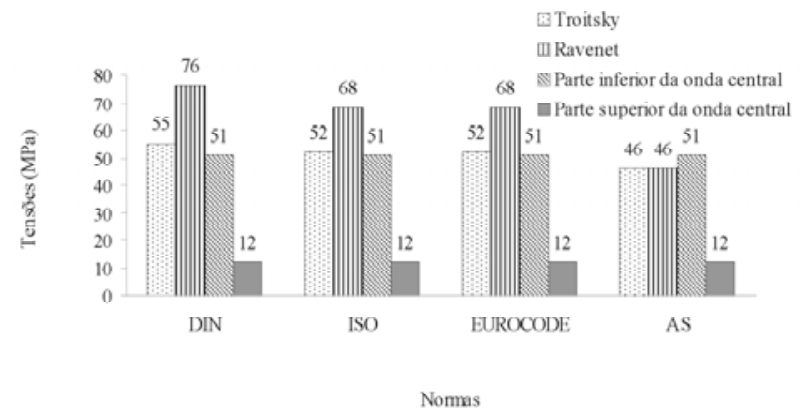

Figura 8 - Tensões estáticas (Parede II)

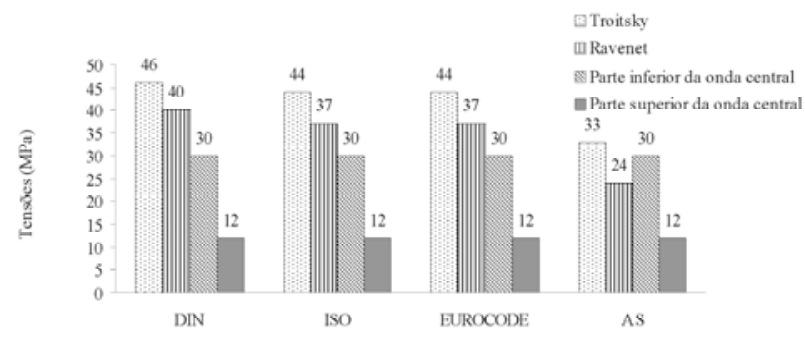

Figura 10 - Tensões estáticas (Parede I)
Na Fase 24 horas (Figura 10), pode-se observar que a teoria de Troitsky, em combinação à norma AS 3774 (AS, 1990), foi a que mais se aproximou aos valores de tensão experimentais para a condição estática na Parede I, superestimando-os em 10\%. Para as tensões no descarregamento (Figura 11), a teoria de vigas biengastadas de Ravenet em conjunto à norma AS 3774 (AS, 1990) foi a mais adequada dentre as demais.

Para as tensões no carregamento na Parede II (Figura 12), o resultado obtido pela teoria de Troitsky, em combinação às normas ISO 11697 (ISO, 1995) e

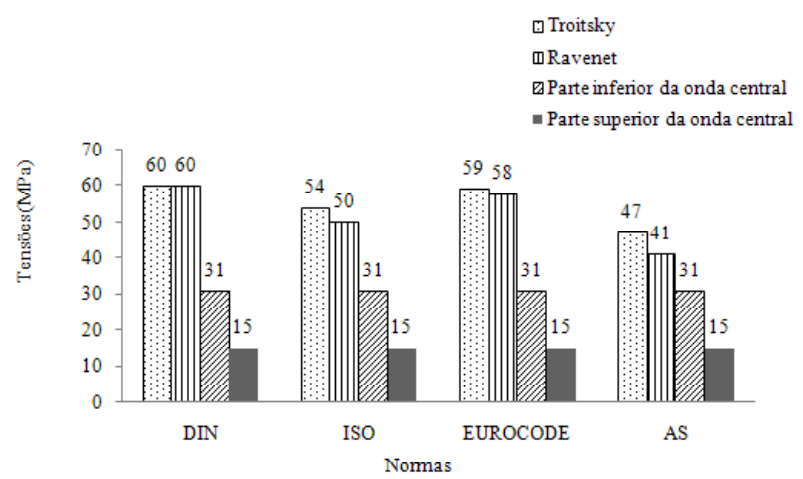

Figura 7 - Tensões dinâmicas (Parede I)

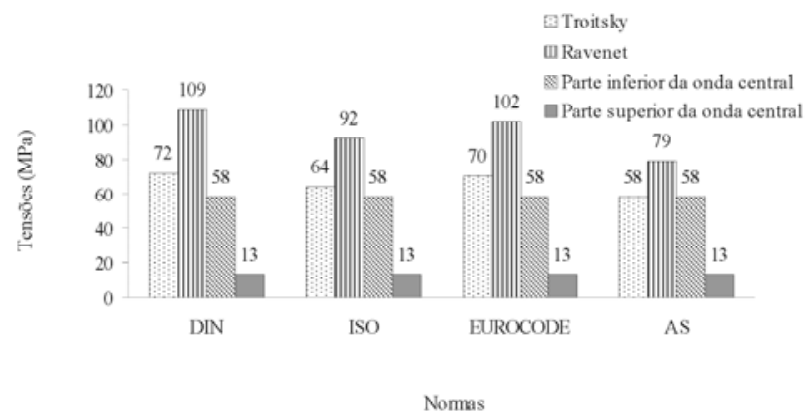

Figura 9 - Tensões dinâmicas (Parede II)

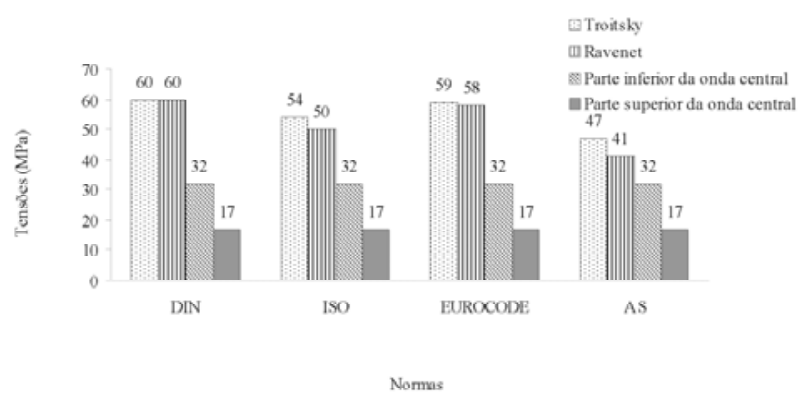

Figura 11 - Tensões dinâmicas (Parede I) 
EUROCODE 1 (EUROCODE, 1995), foi o que melhor representou as tensões reais. Para o descarregamento (Figura 13), a teoria de Troitsky em conjunto à norma ISO 11697 (ISO, 1995) obteve a menor diferença, ficando cerca de $3 \%$ acima dos valores experimentais.

Na Fase 48 horas, pode-se observar na Figura 14 que a combinação Troitsky e AS 3774 (AS, 1990) obteve melhor comportamento para o carregamento, ficando $14 \%$ acima das tensões experimentais na Parede I, entretanto, em análise ao descarregamento (Figura 15), a teoria de Ravenet, em conjunto à norma AS 3774 (AS, 1990) foi a que melhor representou os esforços na parede do silo, sendo cerca de $25 \%$ superior à máxima tensão experimental.

Para a Parede II (Figura 16), a combinação da teoria proposta por Troitsky e as normas ISO 11697 (ISO, 1995) e EUROCODE 1 (EUROCODE, 1995) obtiveram os valores mais próximos para o carregamento, sendo superior à tensão real cerca de $2 \%$. Para condição dinâmica, Figura 17, a melhor representação dos esforços experimentais foi obtida pela teoria proposta por Troitsky, em conjunto à norma EUROCODE 1 (EUROCODE, 1995).

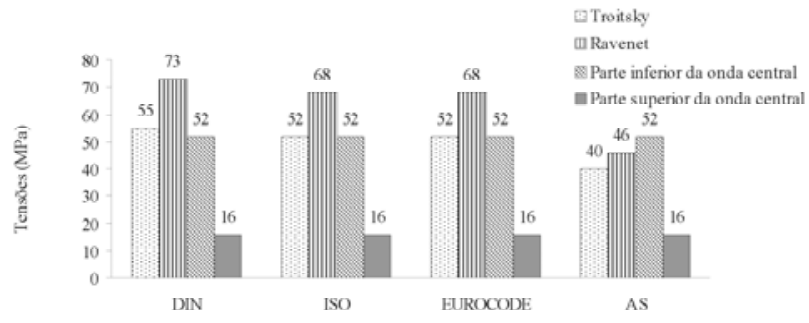

Figura 12 - Tensões estáticas na Parede II

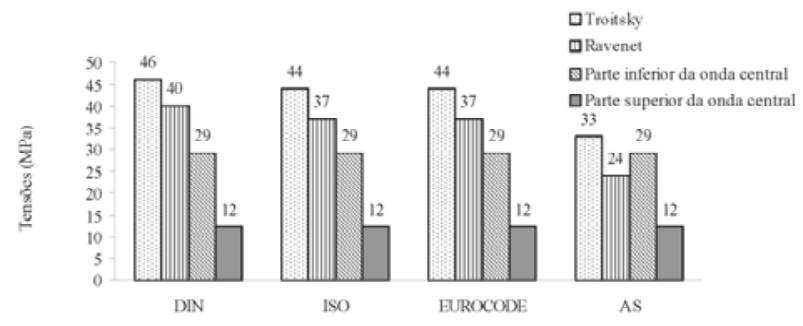

Figura 14 - Tensões estáticas na Parede I

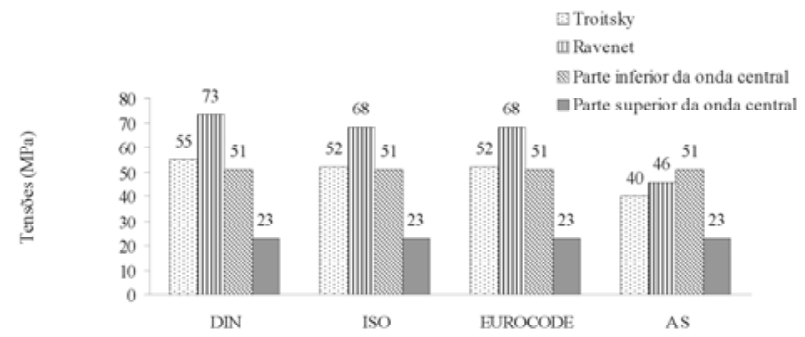

Figura 16 - Tensões estáticas na Parede II

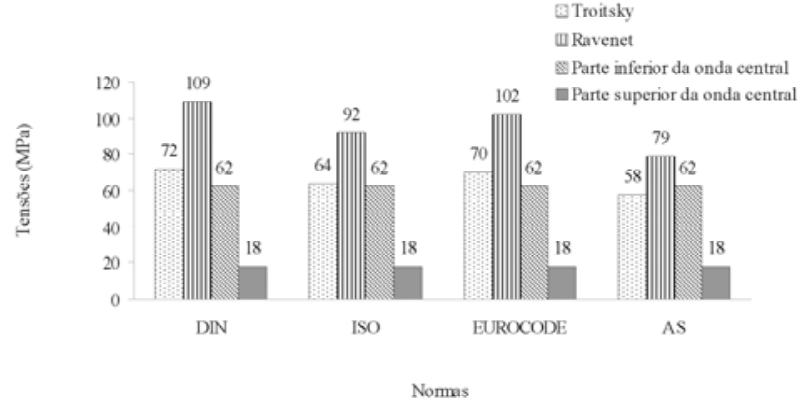

Figura 13 - Tensões dinâmicas na Parede II

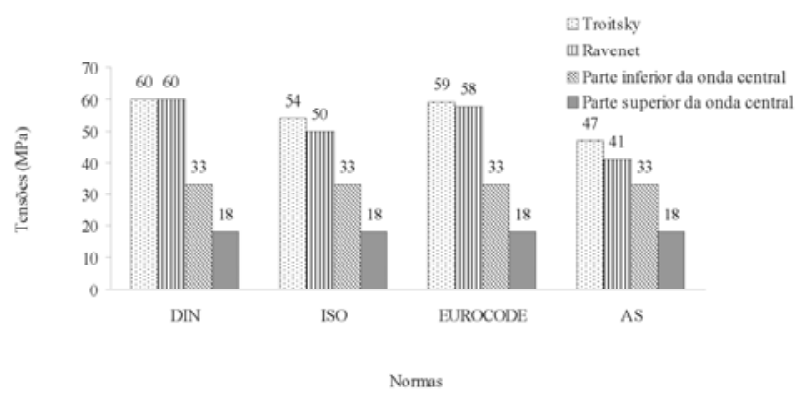

Figura 15 - Tensões dinâmicas na Parede I

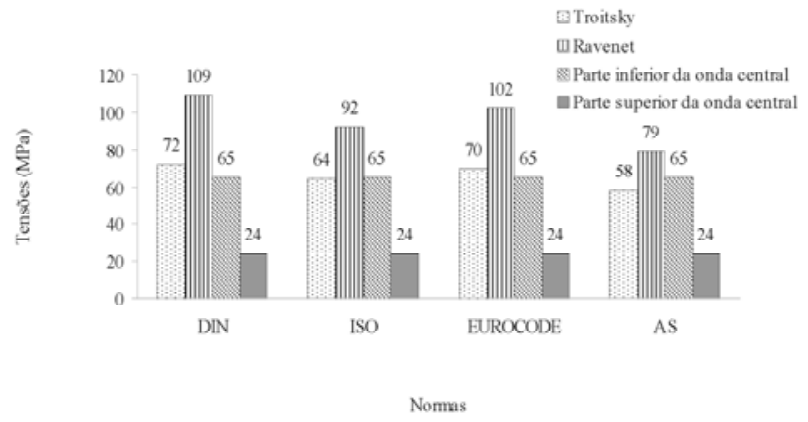

Figura 17 - Tensões dinâmicas na Parede II 


\section{CONCLUSÕES}

Pode-se concluir que o produto utilizado nos ensaios de carga e descarga do silo teste (soja em pelets) não possui característica coesiva com comportamento semelhante aos produtos granulares; que os maiores esforços nas paredes do silo ocorreram na parte inferior da onda central, em virtude da conformação ziguezague; que as tensões nas paredes do silo, na condição dinâmica, foram superiores às estáticas nas duas paredes em todas as fases estudadas; de acordo com as análises teórica e experimental, as teorias simplificadas de Ravenet (1992) e Troitsky (1982) podem ser recomendadas ao dimensionamento de silos metálicos prismáticos.

\section{AGRADECIMENTOS} pesquisa.

À CAPES e CNPq, pelo apoio oferecido para essa

\section{REFERÊNCIAS BIBLIOGRÁFICAS}

AUSTRALIAN STANDARD. AS 3774: loads on bulk containers. Sydney, 1990.

BANDEIRA, I. S. A.; NASCIMENTO, J. W. B.; SILVA, F. A. $\mathrm{S}$. Análise de fluxo de ração e farelo de trigo em silos prismáticos industriais. Revista Brasileira de Engenharia Agrícola e Ambiental, Campina Grande, v. 3, n. 2, p. 233238, 1999.

BRITISH MATERIALS HANDLING BOARD. Draft code of practice for the design of silos, bins, bunkers and hoppers. Berkshire, 1985.

BROWN, C. J.; NIELSEN, J. Silos: fundamentals of theory, behaviour and design. London: E \& FN SPON, 1998. 836 p.
CALIL JUNIOR, C. Sobrepeciones em las paredes de los silos para almacenamiento de productos pulverulents cohesivos. 1984. Tese (Livre Docência) - Escola de Engenharia de São Carlos, Universidade de São Paulo, São Carlos, 1984.

CALIL JUNIOR, C.; NASCIMENTO, J. W.; ARAÚJO, E. C. Silos metálicos multicelulares. São Carlos: EESC/USP, 1997. $178 \mathrm{p}$.

DEUTSCHE NORM. DIN 1055: design loads for buildings: loads in silo bins. Berlin, 1987.

EUROCODE. ENV 4: actions on silos and tanks. Bruxelas, 1995.

INTERNATIONAL STANDART. ISO 11697: bases for design of structures: loads due to bulk materials. Switzerland, 1995.

NASCIMENTO, J. W. B. Estudos de silos metálicos prismáticos para fábricas de ração. 1996. Tese (Doutorado em Engenharia de Estruturas) - Escola de Engenharia de São Carlos, Universidade de São Paulo, São Carlos, 1996.

NASCIMENTO, J. W. B.; CALIL JUNIOR, C. Painéis estruturais para paredes de silos verticais prismáticos. Caderno de Engenharia da Estruturas, São Carlos, n. 6, p. $1-21,1998$.

RAVENET, J. Silos. Barcelona: Editores Técnicos Asociados, 1992. 508 p.

TROITSKY, M. S. Tubular steel structures. Montreal: Concordia University, $1982.89 \mathrm{p}$. 